\title{
Numerical and Experimental Investigation of Wrinkling Pattern for Aerospace Laminated Membrane Structures
}

\author{
Yihong Hong, ${ }^{1,2}$ Wenjuan Yao, ${ }^{1}$ and $Y_{\text {an }} \mathrm{Xu}^{3}$ \\ ${ }^{1}$ Department of Civil Engineering, Shanghai University, Shanghai 200072, China \\ ${ }^{2}$ School of Architectural Engineering, Quzhou University, Zhejiang 324000, China \\ ${ }^{3}$ School of Aeronautics and Astronautics, Zhejiang University, Hangzhou 310027, China
}

Correspondence should be addressed to Wenjuan Yao; wjyao@shu.edu.cn

Received 1 October 2016; Revised 26 March 2017; Accepted 9 April 2017; Published 6 June 2017

Academic Editor: Christian Circi

Copyright (C) 2017 Yihong Hong et al. This is an open access article distributed under the Creative Commons Attribution License, which permits unrestricted use, distribution, and reproduction in any medium, provided the original work is properly cited.

\begin{abstract}
Al-polymer laminated membranes are widely used in large aerospace structures. When the laminated membranes are pressurized, wrinkles emerge, which have an important effect on the performance of the structures during operation. This paper describes the numerical simulation and experimental investigation of wrinkles in laminated membranes. The nonlinear postbuckling analysis method, based on laminated thin-shell elements, was used to simulate the onset, growth, and final configuration of wrinkles when laminated membranes are subjected to external loads. The simulations are conducted with the ANSYS finite element package. Changing regularities of number, wavelength, and range for the wrinkles during the onset and growth processes are investigated. The wrinkles of laminated membranes with different design parameters such as material selection, ply number, ply angle, and ply mode are predicted. Devices that can be used to clamp and load laminated membranes in several load cases were designed and developed. A 3D photogrammetry system was constructed to characterize wrinkling patterns of laminated membranes subjected to shear displacement loads. By comparing the results of numerical analysis and experimental results, the accuracy of the numerical analysis method was verified. This study work is expected to inform wrinkling simulation and shape control of aerospace laminated membrane structures.
\end{abstract}

\section{Introduction}

To design large, lightweight aerospace structures, membrane structure technology is an ideal choice. The development of space membrane structures drives the construction technology of ultralarge aerospace structures; consequently, the potential for damage to large membrane structures can be expected to increase in future aerospace projects. Space membrane structures have many advantages, including lower manufacturing cost, lighter weight, and smaller launch volume. They have been applied in inflatable antennas [1], sunshields, inflatable aerodynamic decelerators, inflatable inhabited structures, and sail arrays. Flexible laminated membranes, particularly Al-Kapton membranes and Al-Mylar membranes, have received much attention in the fabrication of flexible thermal protection systems in sunshield structures, supersonic inflatable aerodynamic decelerators [2], inflatable modules, and lunar habitats [3].
The wrinkles of thin membranes have been analyzed in many stages, and multiple theoretical approaches have been developed. The Tension Field (TF) theory and Iterative Membrane Properties (IMP) method are effective in predicting the wrinkling regions and direction of membrane structures $[4,5]$. However, the geometric features of the wrinkles, that is, the amplitude and wavelength, cannot be simulated by these methods. To accurately predict the wrinkling patterns, another representation of membrane wrinkling can be obtained by using buckling and postbuckling analysis coupled with shell elements possessing bending stiffness. Eigenvalue buckling analysis results are introduced as geometrical imperfections into the initial mesh to perform a postbuckling analysis. Specifically, Wong and Pellegrino [6] conducted the postbuckling analysis of the finite element nodes in terms of a combination of buckling mode shapes. Instead of buckling mode shapes, Jenkins et al. [7] introduced randomly artificial imperfections into the initial membrane, which is a more 
computationally efficient approach because it does not require a separate eigenvalue buckling analysis. The wrinkled membranes have been simulated by directly minimizing the total potential energy, instead of satisfying the equilibrium equations as done with the usual finite element method [8]. And the wrinkling procedure is simply started by applying small random displacement imperfections in the initial membrane surface. Using locking-free shell elements with hourglass control [9], ABAQUS S4R5, a quasi-static analysis of a corner-loaded square membrane was successfully performed. An explicit nonlinear finite element code, DYNA3D, has been performed for wrinkling phenomena of a modeled ballute system [10]. DYNA3D's feasibility in wrinkling modeling is carefully investigated through a rectangular membrane under simple shear.

The dynamic relaxation (DR) method has also been applied to the wrinkling patterns [11]. In the DR method, a static equilibrium solution is obtained by a dynamic transient analysis. The DR method is more stable than postbuckling analysis method for wrinkling analysis to obtain the static equilibrium solution. However, the major shortcoming of the DR method is that longer computation time is required to obtain the converged solution. To overcome this shortcoming, Kashiwa and Onoda [12] have proposed a mixed algorithm combining the DR method and Newton-Raphson (NR) method. The proposed algorithm can improve the convergence speed of the DR method without detracting the analysis stability of the DR method. A stabilized pseudodynamic solution procedure, obtained by setting the mass matrix to zero and using an arbitrary damping matrix, has been presented to stabilize solution procedures [13]. Newmark scheme was used to calculate the solution of the dynamic system.

Most studies of wrinkling patterns assume a single polymer membrane; few studies have investigated wrinkles in laminated membranes. As mentioned above, most membrane materials used in large aerospace structures are laminated membranes. Thus, it is necessary to study the wrinkles of laminated membranes. This paper reports a recently conducted effort of numerical simulation and experimental study of the wrinkled laminated membranes. The influences of initial prestress load, geometric imperfection, and membrane thickness and design parameters of laminated membranes such as material selection, ply number, ply angle, and ply mode are investigated in detail.

The remainder of this paper consists of six sections. Section 2 presents the nonlinear postbuckling analysis method to simulate the wrinkling pattern of laminated membranes. Section 3 covers the design, manufacturing, and assembly of clamping and loading devices for laminated membranes and $3 \mathrm{D}$ photogrammetry system that were used for the measurement testing of wrinkled laminated membranes. Section 4 compares the results of numerical results and experimental results of Al-Kapton laminated membrane in simple shear. Section 5 describes the changing characteristics of wavelength and range for the wrinkles during the onset and growth processes. The influence of initial prestress load, geometric imperfection, and membrane thickness on the wrinkling patterns was investigated. Section 6 presents the influence of design parameters of laminated membranes on the wrinkling pattern. Finally, Section 7 summarizes concluding remarks and suggestions for future work.

\section{Wrinkling Analysis of Laminated Membranes}

The objective of this section is to explore the numerical simulation method of wrinkling patterns in which the laminated membrane is modeled with a fine mesh of laminated shell elements. It also presents the material properties of AlKapton laminated membranes.

2.1. Nonlinear Postbuckling Analysis Method. The shapes of the wrinkles, that is, amplitude and wavelength, can be simulated using bifurcation analysis coupled with shell elements with nonzero bending stiffness. The simulations are conducted with the ANSYS finite element package, in which the laminated membrane is modeled with SHELL181 laminated shell elements. The prestress and initial imperfections are considered in the nonlinear postbuckling analysis.

The nonlinear postbuckling analysis is conducted with the following three steps: (1) a uniform prestress is imposed on the laminated membrane; (2) an initial imperfection or perturbation is used to change the initial configuration of the membrane; and (3) postbuckling analysis is performed to predict the wrinkling patterns.

In the first step, the laminated membrane is subjected to a uniform prestress. The reason is that the membrane is a thin film; thus, the elements have very little bending stiffness. This prestress has an influence when applying the in-plane loads and improves the bending stiffness of membrane structures.

Taking the plane laminated membrane subjected to simple shear as an example, the prestress can be defined in different ways. One is imposing a displacement load on the boundary; the other is defining the initial stress of the shell elements. Subsequently, the uniform prestress is saved as a.ist file in ANSYS software. In the following analysis steps, this file will be read frequently. When the prestress is imposed, bending stiffness of the structures will be improved, and the eigenvalue buckling analysis can be performed.

The laminated membrane structures will not buckle and form wrinkles unless there are imperfections that can trigger an out-of-plane deformation. There are two types of imperfections as follows: one is an initial geometrical imperfection and the other is an artificial force imperfection. (1) The eigenvalues are generated through eigenvalue buckling analysis. It is important that the initial stresses, the displacement, and the boundary conditions are included in the eigenvalue buckling analysis. After the possible wrinkling mode shapes are calculated, a linear combination of certain selected eigenmodes is introduced as a geometrical imperfection with normalized magnitude of $10-100 \%$ of the membrane thickness in the postbuckling analysis. (2) The out-of-plane artificial force imperfections are imposed in the possible wrinkle region. When the artificial force imperfections are introduced, the force equilibrium conditions will be satisfied to avoid macroscopic deformations of laminated membranes. The effects of 


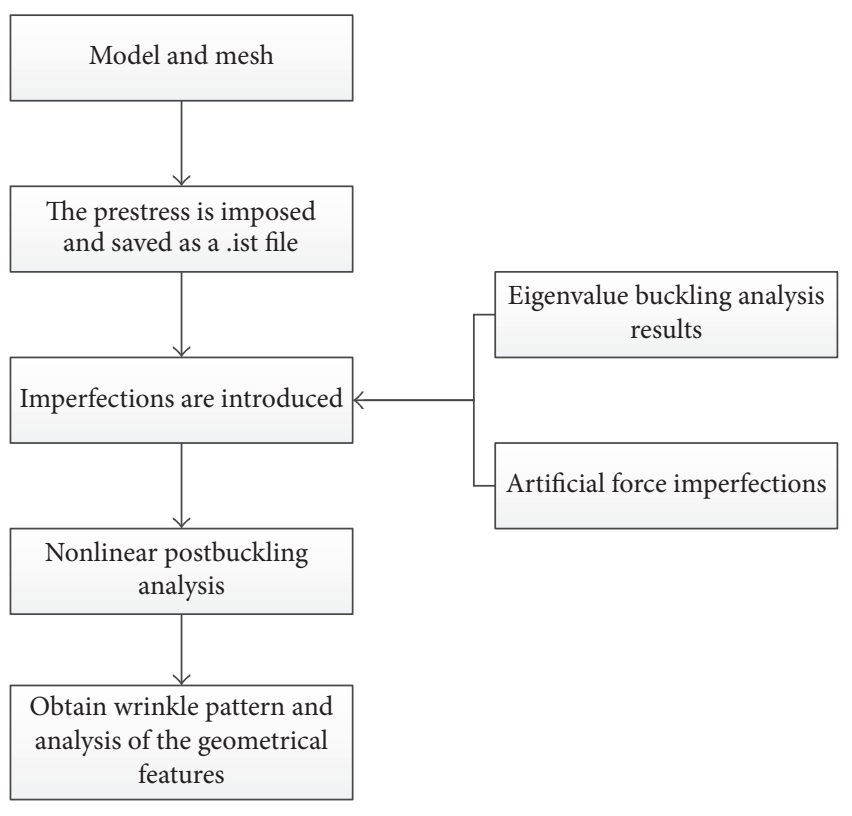

FIGURE 1: Flow chart for wrinkling pattern simulation.

these artificial imperfections need to be investigated, and a certain range of artificial imperfections will be obtained.

A geometrically nonlinear postbuckling analysis is carried out while increasing force loads or displacement loads. It can be challenging to achieve convergence in a nonlinear postbuckling analysis. To guarantee convergence, it is necessary to set the correct load step and substeps in each load step. Unfortunately, all attempts to use the arc-length solution method and Newton-Raphson solution method were unsuccessful because wrinkling is a highly localized type of instability. Automatic stabilization was provided through the STABILIZE function in ANSYS. Damping was initially introduced into the model through STABILIZE, which introduces pseudoinertia and pseudoviscous forces at all nodes when instability is detected. To avoid influencing the final analysis result, it is generally desirable to set this parameter to the lowest possible value.

The flow chart for wrinkling pattern simulation based on nonlinear postbuckling analysis method is shown in Figure 1.

\subsection{Finite Element Models of Laminated Membranes. The Al-} polymer laminated membrane material is developed by laminating the extendable aluminum film and the polymer film (such as Mylar and Kapton). The polymer film is used to seal the gas, and the aluminum film in which the residual strain is produced is used to provide stiffness. Because micropores can easily be produced when aluminum films are folded, polymer films can increase the tensile capacity of the aluminum film and improve the material performances. Due to their desirable characteristics, Al-polymer laminated membranes have been used in many large-scale inflatable spacecraft structures. $\mathrm{Al}$-Kapton laminated membranes investigated in the paper are a representative type. The mechanical properties of each component material and Al-Kapton laminated membranes are listed in Table 1 [14].

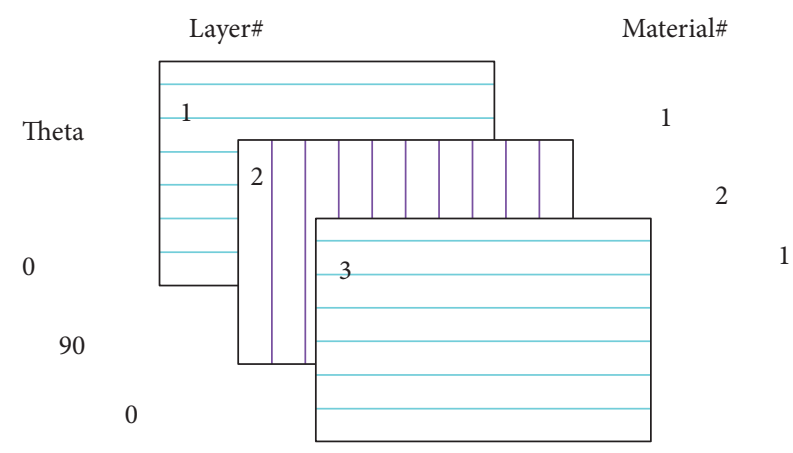

FIGURE 2: Layer parameters of laminated membranes.

The Al-Kapton laminated membranes are a type of composite material. The laminated thin-shell element SHELL181, a type of finite strain shell element, is used to model the laminated membranes in ANSYS. SHELL181 is a 4-node 3D shell element in which each node has six degrees of freedom; it can simulate more than 255 layers. Thus, it has been widely used in the composite material analysis of thin-shell structures. It is straightforward to design the layer parameters of the laminated film, such as the individual component material, layer sequences, and layer angles, and display them intuitively in the graphics window, as shown in Figure 2.

The size of the elements is related to the expected wrinkling pattern and wavelength. The reason for this is that a complete wrinkle wave requires more than four elements to avoid disturbing the numerical calculations.

\section{Wrinkling Pattern Measurement by Photogrammetry}

3.1. Photogrammetry System. Because the laminated membranes are thin and lightweight, a measurement process based on contact techniques will undesirably affect the wrinkling pattern; thus, it is necessary to construct a noncontact wrinkling pattern measuring system. The measuring system includes the following components: clamping and loading devices for laminated membranes, an OpticScan-QL 3D scanning system based on four-view monocular vision, and graphing postprocess software, as shown in Figure 3. The raster scanning technique is used in the OpticScan-QL 3D scanning system. The surfaces can be measured by noncontact methods, and the graphical data can be spliced together into a single image. The primary technical parameters of the scanning system are shown in Table 2 . The wrinkling pattern measuring system has advantages such as high efficiency, high precision, long lifetime, and high resolution; it is suitable for measurement, detection, and reverse modeling of complex free-form surfaces.

3.2. Clamping and Loading Devices. The clamping and loading devices for laminated membranes, shown in Figure 4, consist of an SB102 optical plate, PTS300 series high-precision displacement platform, and a set of customized clamps for holding the membrane. The SB102 optical plate is used as the base of the devices, and two sets of PTS300 displacement 
TABLE 1: Mechanical properties of each component and Al-Kapton membrane [14].

\begin{tabular}{lcccccc}
\hline Material & $\begin{array}{c}\text { Thickness } \\
(\mathrm{mm})\end{array}$ & $\begin{array}{c}\text { Modulus of elasticity } \\
(\mathrm{GPa})\end{array}$ & $\begin{array}{c}\text { Tensile strength } \\
(\mathrm{MPa})\end{array}$ & $\begin{array}{c}\text { Yield strength } \\
(\mathrm{MPa})\end{array}$ & $\begin{array}{c}\text { Elastic deformation } \\
(\%)\end{array}$ & $\begin{array}{c}\text { Tensile elongation yield } \\
(\%)\end{array}$ \\
\hline 1050A aluminum film & 0.075 & 35.91 & 92.9 & 46.30 & 174 & 7 \\
Kapton membrane & 0.025 & 3.58 & 186.0 & 12.1 & 1.44 & 37.0 \\
$\begin{array}{l}\text { Kapton membrane } \\
\begin{array}{l}\text { Al-Kapton laminated } \\
\text { membrane }\end{array}\end{array}$ & 0.050 & 4.91 & 132.0 & 6.8 & 1.38 & 47.0 \\
\hline
\end{tabular}

TABLE 2: Main technical parameters of the scanning system.

\begin{tabular}{lc}
\hline Type & OpticScan-QL \\
\hline Single-scanned area & $400 \mathrm{~mm} \times 300 \mathrm{~mm} \sim 200 \mathrm{~mm} \times$ \\
Single scanning accuracy & $0.04 \mathrm{~mm}$ (adjusted) \\
Mean sampling point pitch & $0.015 \mathrm{~mm} \sim 0.15 \mathrm{~mm}$ \\
Size of scanned object & $200 \mathrm{~mm} \sim 1,500 \mathrm{~mm}$ \\
& (photogrammetry system is used \\
Scanning mode & When larger than 1,500 mm) \\
& photograph \\
Data splice method & Full-automatic splicing based on \\
Image resolution & mark points \\
Output document format & 1.31 million pixels \\
Single scanning time & ASC, STL \\
\hline
\end{tabular}

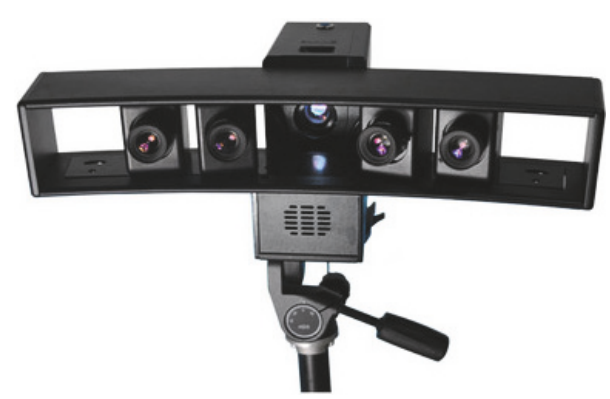

FIgURE 3: OpticScan-QL 3D scanning system.

platforms are mounted on the optical plate. These platforms guarantee that the devices are supported by a precise horizontal plane. Two sets of long strip clamps are connected to these displacement platforms; they consist of two demountable top and bottom strips with bolt holes. When a laminated membrane sample is clamped between the top and bottom strips, the long strip clamps are connected as an entire device by tightening these bolts. To clamp the laminated membrane effectively, the bottom surface of the top strip and the top surface of the bottom strip are rough.

These clamp and loading devices can be applied to wrinkling pattern measurement in multiple load cases. Taking the plate membrane subjected to simple shear load as an example, a PTS308M-type displacement platform was adopted as the number 2 displacement platform, which is used to control
TABLE 3: Technical characteristics of SB102 optical plate.

\begin{tabular}{lc}
\hline Type & SB102 \\
\hline Size of table board $(\mathrm{mm})$ & $300 \times 600 \times 13$ \\
Flatness & $0.08 \mathrm{~mm} / \mathrm{m}^{2}$ \\
Pitch row & $25 \mathrm{~mm} \times 25 \mathrm{~mm}$ \\
Aperture & M6 \\
Material & High-quality aluminum alloy \\
\hline
\end{tabular}

TABLE 4: Technical characteristics of PTS300 series displacement platform.

\begin{tabular}{lcc}
\hline Type & PTS307M & PTS308M \\
\hline Size of table board $(\mathrm{mm})$ & $90 \times 90$ & $90 \times 90$ \\
Stroke $(\mathrm{mm})$ & 25 & 25 \\
Drive method & $\begin{array}{c}\text { Micrometer } \\
\text { heads }\end{array}$ & $\begin{array}{c}\text { Micrometer } \\
\text { heads }\end{array}$ \\
Precision $(\mathrm{mm})$ & 0.003 & 0.003 \\
Resolution ratio $(\mathrm{mm})$ & 0.002 & 0.002 \\
Minimum scale $(\mathrm{mm})$ & 0.01 & 0.01 \\
Drive location & Center & Side face \\
Maximum central loading $(\mathrm{kg})$ & 15 & 15 \\
Dead load $(\mathrm{kg})$ & 0.9 & 0.9 \\
\hline
\end{tabular}

the stretch displacement of the laminated membranes for applying prestress. The PTS307M-type displacement platform was adopted as the number 1 displacement platform, which is used to apply shear displacement load of laminated membranes. The prestress and the shear load can be applied precisely by driving the micrometer heads in manual operation.

The technical characteristics of the SB102 optical plate and PTS300 series high-precision displacement platform are provided in Tables 3 and 4, respectively.

3.3. Wrinkling Pattern Measurement. The wrinkling pattern measurement was conducted based on the photogrammetry system. Taking the plate membrane subjected to simple shear load as an example, the test steps are described as follows:

(1) The 3D scanning system and software were opened, and the cameras and projector were calibrated using a calibration board.

(2) The geometric dimensions of the test model were designed, and the laminated membrane was cut. 


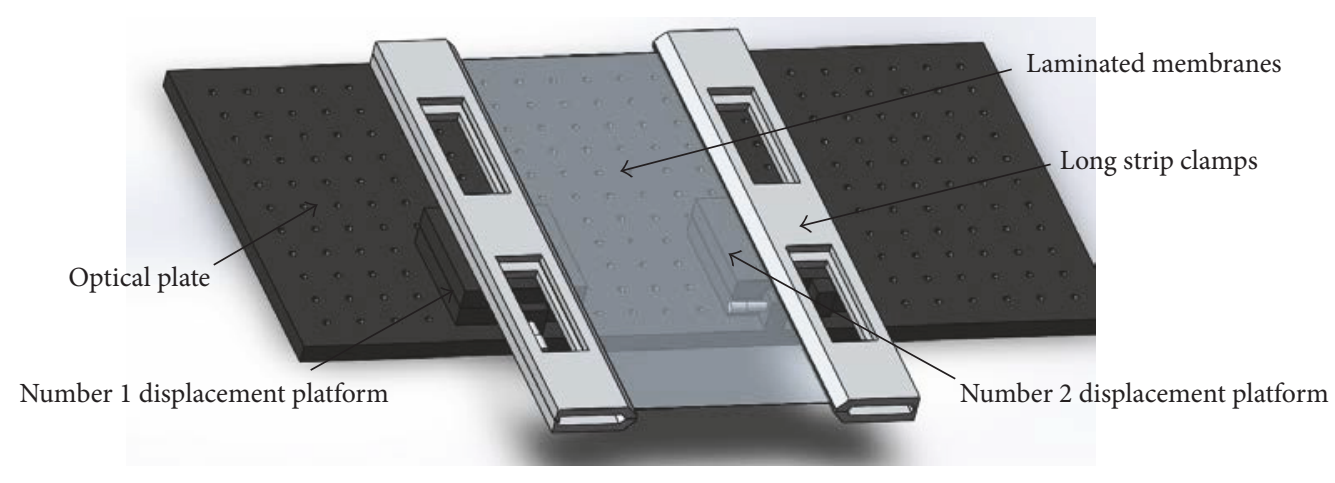

FIgURE 4: Clamping and loading devices.

Sometimes the developer was used to dye the laminated membrane to avoid excessive transparency of the membrane.

(3) The distance between the number 1 and number 2 displacement platforms was set. The long sides of the rectangular laminated membrane were clamped by two long strip clamps. The entire clamping and loading devices were installed as shown in Figure 4.

(4) The micrometer heads in the number 2 displacement platform were driven to move the platform, and the laminated membrane was tensioned slightly. The clamping status of the membrane model was examined.

(5) The micrometer heads in the number 2 displacement platform were driven to move the platform, and the laminated membrane was tensioned $0.05 \mathrm{~mm}$ along the $y$-direction to apply the prestress.

(6) The micrometer heads in the number 1 displacement platform were driven to move the platform to apply shear loading $3 \mathrm{~mm}$ along the $x$-direction. The resulting wrinkling pattern is shown in Figure 5.

(7) The strong reflective marking points were pasted on the laminated membrane surface in random locations.

(8) The wrinkling patterns of laminated membranes were scanned by the calibrated $3 \mathrm{D}$ scanning system. The proper points of view were chosen to enable distinct scan imagery, as shown in Figure 6.

(9) The wrinkling patterns were scanned along 8 points of view, and the scan images were obtained. The entire surface was automatically spliced in the software. Finally, the point cloud data were obtained.

(10) Postprocessing of the point cloud data, such as denoising, smoothing, and filling of the marked point holes, was conducted by Geomagic software. The three-dimensional surface model was then rebuilt.

(11) The three-dimensional surface of wrinkling pattern was obtained, as shown in Figure 7, enabling analysis of the geometrical features.

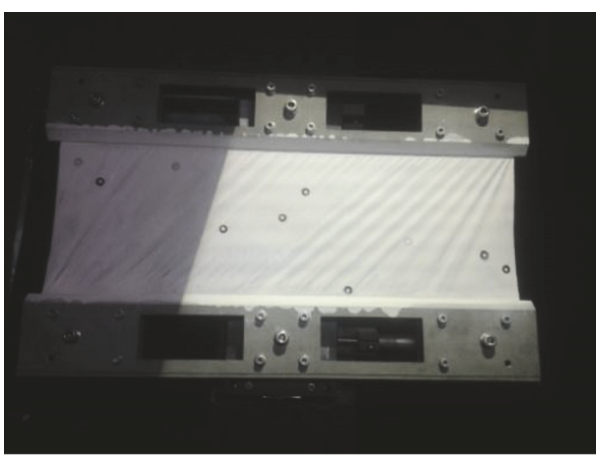

FIGURE 5: Wrinkling of the clamped membrane.

\section{Al-Kapton Laminated Membrane in Simple Shear}

4.1. Numerical Analysis Results. A rectangular Al-Kapton laminated membrane with a length of $380 \mathrm{~mm}$ and a width of $128 \mathrm{~mm}$ was subjected to simple shear load, as shown in Figure 8 . The laminated membrane consisted of two Kapton layers with a thickness of $0.025 \mathrm{~mm}$ per layer in the outer layers and one aluminum layer with a thickness of $0.075 \mathrm{~mm}$ in the middle layer. Thus, the whole thickness of laminated membranes was $0.125 \mathrm{~mm}$ without including the bonding layers; the mechanical properties of each component are provided in Table 1.

The laminated shell element SHELL181 with 4 nodes and six degrees of freedom per node was used to model the AlKapton laminated membrane. The number of elements was set to 12,160 elements; the FEM model is shown in Figure 9.

In the first step, the prestress load was applied to the AlKapton laminated membrane by imposing displacement of $0.05 \mathrm{~mm}$ on the upper edge, which is shown in Figure 10. The displacement is applied incrementally over 20 steps. To produce a uniform prestress, the boundaries on the left and right edge, denoted, respectively, as number 1 edge and number 3 edge in Figure 8, are locked to prevent the edges from moving and forming a waist on the membrane. Upper edge displacement of $0.05 \mathrm{~mm}$ generates a prestress in the membrane of approximately $\sigma_{y}=1.58 \mathrm{MPa}$. The results of prestress in the 


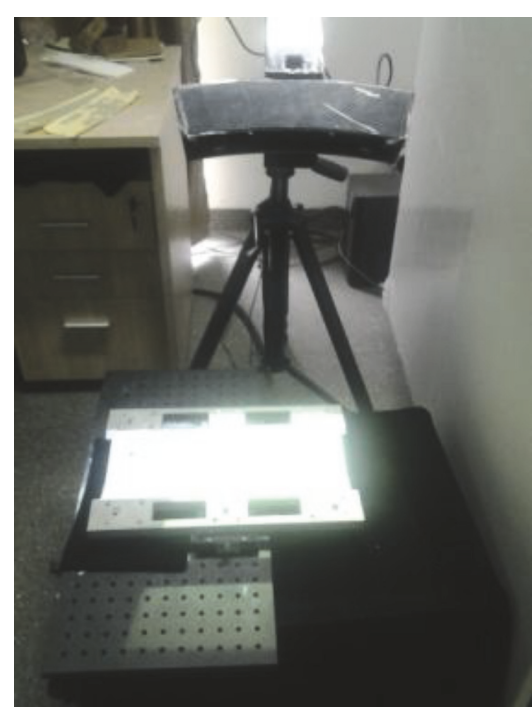

FIGURE 6: Wrinkling pattern scanning.

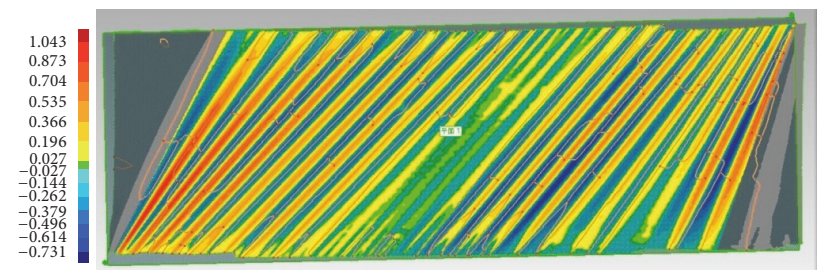

FIGURE 7: Three-dimensional surface wrinkling pattern.

TABLE 5: Eigenvalues near 0.01 .

\begin{tabular}{lc}
\hline Number & Eigenvalues \\
\hline 1 & $7.574 e-3$ \\
2 & $7.580 e-3$ \\
3 & $9.022 e-3$ \\
4 & $9.163 e-3$ \\
5 & $1.159 e-2$ \\
6 & $1.168 e-2$ \\
7 & $1.508 e-2$ \\
8 & $1.541 e-2$ \\
\hline
\end{tabular}

membrane are saved as a ist file, which will be reread in the following steps.

In the second step, the Lanczos eigensolver is used to produce eigenvalues in a certain range. Here, the solver was set to produce 8 eigenvalues near 0.01 . Lower eigenvalues were assumed to represent local buckling modes of the membrane. The eigenvalues and eigenvectors of the tangent stiffness matrix for the structures correspond to the load magnitude and buckling mode shapes of the membrane. Eight eigenvalues near 0.01 are shown in Table 5, and the corresponding mode shapes are shown in Figure 11.

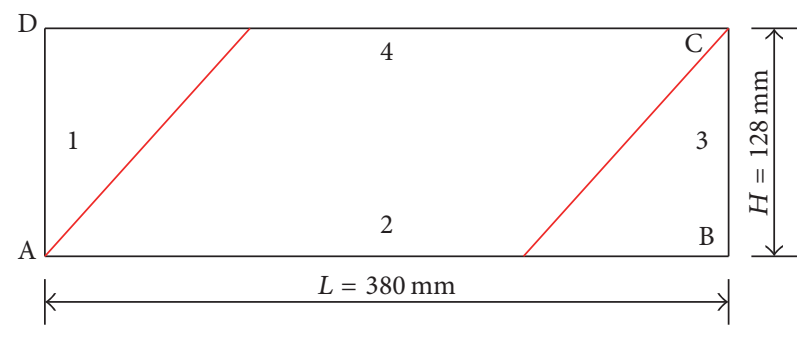

FIGURE 8: Rectangular Al-Kapton laminated membrane.

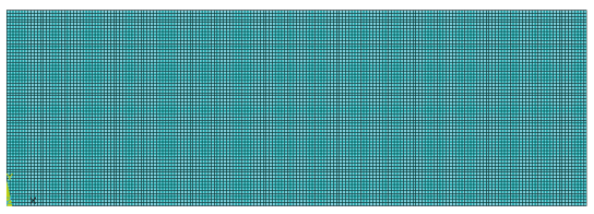

FIGURE 9: FEM model of the membrane.

After the possible wrinkling mode shapes are calculated, a linear combination of these selected eigenmodes is introduced to update the configuration of the laminated membrane. Here, the linear combination coefficient is set to be 0.0005 . The initial geometric imperfections were introduced for the following nonlinear postbuckling analysis.

Finally, displacement of $3.0 \mathrm{~mm}$ was applied to the upper edge along the $x$-direction, and then nonlinear postbuckling analysis was conducted to obtain the final three-dimensional wrinkling pattern. The large deformation option NLGEOM was selected, and the NR method was used in the analysis process. The number of load steps was set to 1,000; there were 500 substeps in each load step. The STABILIZE function parameter was set to be 0.00018 when an instability was detected. If the nonlinear analysis process did not converge, the analysis was restarted at the load step before convergence failed. The out-of-plane displacement of the Al-Kapton laminated membrane after the wrinkle appears is shown in Figure 12. To visualize the wrinkling pattern effectively, the out-of-plane displacement shown in the figure is magnified tenfold.

As shown in Figure 12, there were 12 wrinkles when the laminated membrane was subjected to shear displacement of $3.0 \mathrm{~mm}$ on the upper edge along the $x$-direction. The average range of these wrinkles is $0.819 \mathrm{~mm}$, and the half wavelength is $15.67 \mathrm{~mm}$.

4.2. Comparison of Experimental Results and Numerical Results. The wrinkling pattern measurement of the AlKapton laminated membrane subjected to simple shear load, which has the same size and the same material component, was conducted by photogrammetry. The micrometer heads in number 2 displacement platform were driven to move $0.05 \mathrm{~mm}$ along the $y$-direction to apply the prestress. The micrometer heads in the number 1 displacement platform were driven to move $3 \mathrm{~mm}$ along the $x$-direction to induce wrinkling. Scanning, testing, and postprocessing of the threedimensional wrinkling pattern were performed according to the test steps described. From the experimental results, the 


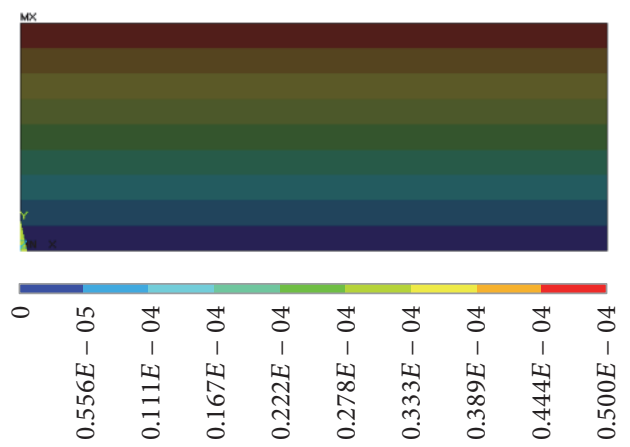

Figure 10: Displacement in the $y$-direction.

number of wrinkles was 12 when the membrane was subjected to $3.0 \mathrm{~mm}$ shear displacement, and the geometric features were close to the numerical results.

To compare the results of numerical results and experimental results more clearly, the wrinkling pattern in the middle section along the $y$-direction $(y=64 \mathrm{~mm})$ of the laminated membrane is displayed in Figure 13. In this figure, the $x$-axis denotes $x$-coordination and $y$-axis denotes out-ofplane deformation $w$. The actual wrinkling pattern agrees well with the corresponding analytical prediction result except for the height and range of the wrinkles in certain areas. The accuracy of the numerical analysis method is thus verified.

\section{Parameters Impact Analysis}

5.1. Shear Displacement Load. We also investigated how the wrinkles form and how the number of wrinkles increases with shear displacement. The wrinkling patterns of the Al-Kapton laminated membrane subjected to shear displacement of 0.1 , $0.2,1.0,1.8,2.6$, and $3.0 \mathrm{~mm}$ were numerically analyzed. The geometrical features in each load case, such as the number of wrinkles, maximum $z$-direction displacement, minimum $z$-direction displacement, average height, and mean half wavelength, were compared, as shown in Table 6.

From the analysis results, it can be observed that new wrinkles were generated and grew along with the increase in the external load. The number of wrinkles, average height, and the maximum/minimum $z$-direction displacement increased. The mean half wavelength decreased, and the wrinkle distribution increased in intensity. After a certain value of loading, the number of wrinkles and mean half wavelength were only minimally affected. However, the average height and the maximum/minimum $z$-direction displacement still grew rapidly.

5.2. Initial Prestress. The initial prestress was applied to AlKapton laminated membranes by imposing tensional displacement on the upper edge. Upper edge displacement of $0.5 \mathrm{~mm}$ generated a prestress in the membrane of approximately $\sigma_{y}=15.8 \mathrm{MPa}$. Then, shear displacement of $0.1 \mathrm{~mm}$ produced a prestress in the membrane of approximately $\sigma_{y}=$ $3.16 \mathrm{MPa}$. The wrinkling patterns were numerically simulated in these two load cases and compared to the case in which the shear displacement was $0.05 \mathrm{~mm}$, as shown in Table 7 .
The results indicate that the number of wrinkles increases and that other geometrical features become smaller when the tensional displacement increases.

5.3. Initial Geometric Imperfections. A linear combination of the selected eigenmodes is introduced to update the configuration of the laminated membrane, and the linear combination coefficient is set to 0.0005 . The maximum range of the geometric imperfections is $\pm 0.035 \mathrm{~mm}$. Then, the linear combination coefficient is set to 0.001 , and the maximum range of the geometric imperfections is $\pm 0.07 \mathrm{~mm}$. The wrinkling patterns were numerically simulated in these two analysis cases, as shown in Table 8.

The results indicate that the initial geometric imperfections did not affect the finial configuration of wrinkles when the geometric imperfections had normalized magnitude of $10-100 \%$ of the membrane thickness.

5.4. Membrane Thickness. The laminated membranes with a thickness of $0.125 \mathrm{~mm}$ were analyzed. The laminated membranes consisted of two Kapton layers with a thickness of $0.05 \mathrm{~mm}$ per layer and one aluminum layer with a thickness of $0.075 \mathrm{~mm}$. The total thickness was $0.175 \mathrm{~mm}$. The wrinkling patterns were numerically simulated in these two load cases, as shown in Table 9.

The results indicate that the number of wrinkles decreases when the thickness of the Kapton layers is increased from $0.025 \mathrm{~mm}$ to $0.05 \mathrm{~mm}$. Simultaneously, the mean half wavelength of all wrinkles increases, as do the geometrical features along the $z$-direction.

\section{Wrinkling Analysis of Laminated Membrane}

For the flexible thermal protection systems, two types of flexible laminated membranes are widely applied, which are Al-Kapton membranes and Al-Mylar membranes. Kapton membranes are isotropic materials and Mylar membranes are orthotropic materials. Mechanical properties of Kapton and Mylar membranes are shown in Table 10. And mechanical properties of $\mathrm{Al}$ film have been listed in Table 1.

There are many design schemes of flexible thermal protection systems based on Al-Kapton and Al-Mylar laminated membranes. The wrinkling pattern of these laminated membrane design schemes is simulated and the design parameters of laminated membranes such as material selection, ply number, ply angle, and ply mode are discussed as follows.

6.1. Wrinkles of Al-Kapton and Al-Mylar Laminated Membrane. Wrinkling patterns of Al-Kapton and Al-Mylar laminated membranes are simulated, respectively. The Al-Kapton laminated membrane consists of two Kapton layers in the outer layers and one aluminum layer in the middle layer. The Al-Mylar laminated membrane consisted of two Mylar layers in the outer layers accordingly. Two laminated membranes are subjected to simple shear displacement of $3.0 \mathrm{~mm}$. The geometrical features of the two wrinkled laminated membranes were compared, as shown in Table 11. 

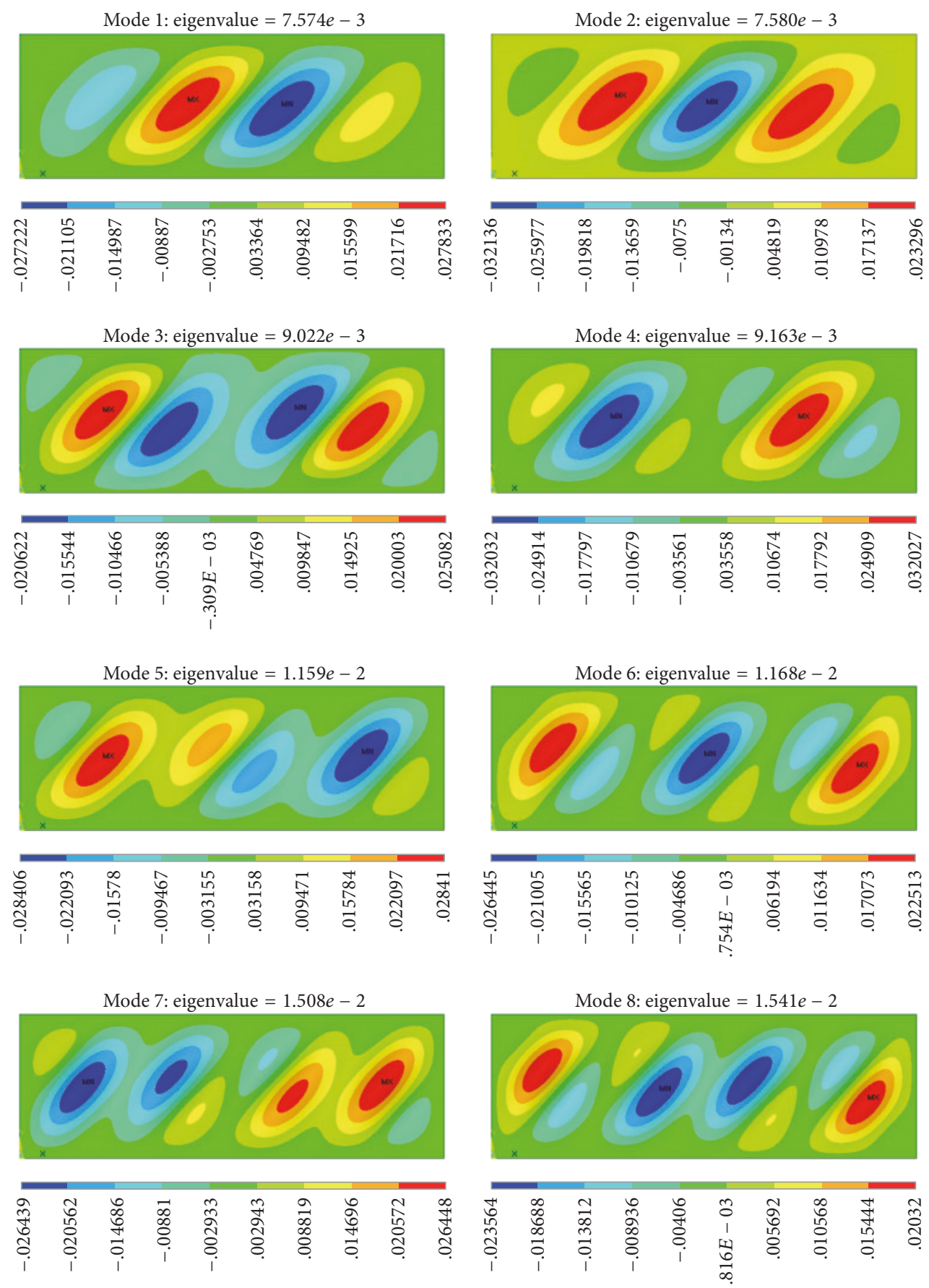

FIGURE 11: Corresponding buckling mode shapes.

TABLE 6: Influence of shear displacement.

\begin{tabular}{lccccc}
\hline $\begin{array}{l}\text { Shear displacement } \\
(\mathrm{mm})\end{array}$ & $\begin{array}{c}\text { Number of } \\
\text { wrinkles }\end{array}$ & $\begin{array}{c}\text { Maximum } z \text {-direction } \\
\text { displacement }(\mathrm{mm})\end{array}$ & $\begin{array}{c}\text { Minimum } z \text {-direction } \\
\text { displacement }(\mathrm{mm})\end{array}$ & $\begin{array}{c}\text { Average height } \\
(\mathrm{mm})\end{array}$ & $\begin{array}{c}\text { Mean half wavelength } \\
(\mathrm{mm})\end{array}$ \\
\hline 0.1 & 5 & 0.221 & 0.226 & 0.135 & 26.2 \\
0.2 & 5 & 0.403 & 0.460 & 0.291 & 25 \\
1.0 & 9 & 0.890 & 0.870 & 0.589 & 18.37 \\
1.8 & 10 & 1.112 & 1.114 & 0.765 & 17.25 \\
2.6 & 10 & 1.29 & 1.24 & 0.795 & 15.67 \\
3.0 & 12 & 1.355 & 1.401 & 0.819 & 15.67 \\
\hline
\end{tabular}


TABLE 7: Influence of initial prestress.

\begin{tabular}{lccccc}
\hline $\begin{array}{l}\text { Tensional } \\
\text { displacement }(\mathrm{mm})\end{array}$ & $\begin{array}{c}\text { Number of } \\
\text { wrinkles }\end{array}$ & $\begin{array}{c}\text { Maximum } z \text {-direction } \\
\text { displacement }(\mathrm{mm})\end{array}$ & $\begin{array}{c}\text { Minimum } z \text {-direction } \\
\text { displacement }(\mathrm{mm})\end{array}$ & $\begin{array}{c}\text { Average height } \\
(\mathrm{mm})\end{array}$ & $\begin{array}{c}\text { Mean half wavelength } \\
(\mathrm{mm})\end{array}$ \\
\hline 0.05 & 12 & 1.401 & 1.355 & 0.819 & 19.67 \\
0.1 & 13 & 1.35 & 1.32 & 0.808 & 14.2 \\
0.5 & 14 & 1.19 & 1.14 & 0.709 & 13.45 \\
\hline
\end{tabular}

TABLE 8: Influence of initial geometric imperfections.

\begin{tabular}{lccccc}
\hline $\begin{array}{l}\text { Combination } \\
\text { coefficient }\end{array}$ & $\begin{array}{c}\text { Number of } \\
\text { wrinkles }\end{array}$ & $\begin{array}{c}\text { Maximum } z \text {-direction } \\
\text { displacement }(\mathrm{mm})\end{array}$ & $\begin{array}{c}\text { Minimum } z \text {-direction } \\
\text { displacement }(\mathrm{mm})\end{array}$ & $\begin{array}{c}\text { Average height } \\
(\mathrm{mm})\end{array}$ & $\begin{array}{c}\text { Mean half wavelength } \\
(\mathrm{mm})\end{array}$ \\
\hline 0.0005 & 12 & 1.401 & 1.355 & 0.819 & 15.67 \\
0.001 & 12 & 1.409 & 1.339 & 0.809 & 15.88 \\
\hline
\end{tabular}

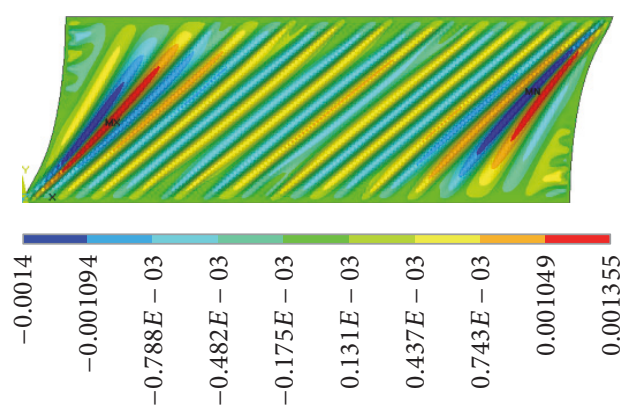

FIGURE 12: Out-of-plane displacement of laminated membrane.

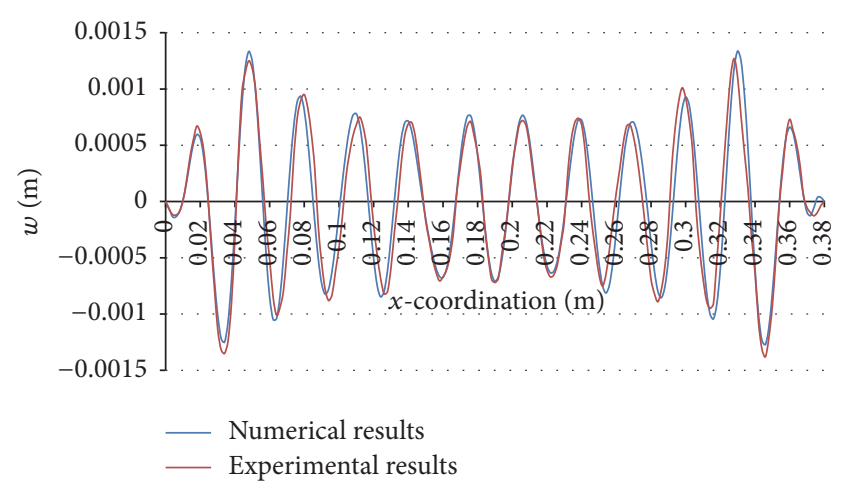

FIGURE 13: Comparing the results of numerical analysis and test results.

The results show that the wrinkling patterns of Al-Kapton and Al-Mylar laminated membranes are similar and the geometrical features are very close. Although Mylar membranes are orthotropic materials, the material properties in two material directions have a little difference. Elastic moduli of Kapton membrane and Mylar membrane are different, but these have a little influence on the wrinkling patterns.

6.2. Wrinkling Pattern of Different Ply Angles. Because Mylar membranes are orthotropic materials, the ply angles of Mylar have an effect on the mechanical behaviors of Al-Mylar laminated membranes. The wrinkling pattern of laminated membranes was analyzed, where ply angles are designed to be 0,45 , and 90, respectively. The geometrical features of the wrinkles were compared, as shown in Table 12.

The geometrical features of laminated membranes change with the change of the ply angles, but the magnitude of change is very small. The reason is that material properties of Mylar in two material directions are very similar.

6.3. Wrinkling Pattern of Different Ply Numbers. For flexible thermal protection systems, a single Al-Kapton laminated membrane cannot resist the severe thermal environment. So, multilayer laminated membranes with different ply numbers are designed. Each sublayer laminated membrane consisted of two Kapton layers and one aluminum layer. The laminated membranes are subjected to simple shear displacement of $3.0 \mathrm{~mm}$. The wrinkled laminated membranes with different ply numbers were simulated and the geometrical characteristics of the wrinkled laminated membranes are shown in Table 13.

From the analysis results, it can be observed that, with the increase of ply numbers, the number of wrinkles becomes smaller. The range and mean half wavelength become larger accordingly. These changes are very obvious. So, the ply number of laminated membranes plays an important role in wrinkle behaviors and needs to be designed carefully.

6.4. Wrinkling Pattern of Different Ply Modes. The effects of ply mode for laminated membranes were investigated. There are three ply modes: in ply mode 1 , laminated membranes consist of three Al-Kapton sublayers; in ply mode 2, laminated membranes consist of two Al-Kapton sublayers in the top/bottom surface and one Al-Mylar in the middle; in ply mode 3, laminated membranes consist of two Al-Mylar sublayers in the top/bottom surface and one Al-Kapton in the middle. The wrinkled laminated membranes with these three ply modes were simulated and the geometrical features of the wrinkle are listed in Table 14.

From the analysis results, wrinkling patterns of ply mode 1 are different from those of the other two ply modes. The wrinkles of ply mode 1 laminated membranes are more and smaller. The wrinkling patterns of ply mode 2 and ply mode 3 are very similar. 
TABLE 9: Influence of membrane thickness.

\begin{tabular}{lccccc}
\hline $\begin{array}{l}\text { Thickness } \\
(\mathrm{mm})\end{array}$ & $\begin{array}{c}\text { Number of } \\
\text { wrinkles }\end{array}$ & $\begin{array}{c}\text { Maximum } z \text {-direction } \\
\text { displacement }(\mathrm{mm})\end{array}$ & $\begin{array}{c}\text { Minimum } z \text {-direction } \\
\text { displacement }(\mathrm{mm})\end{array}$ & $\begin{array}{c}\text { Average height } \\
(\mathrm{mm})\end{array}$ & $\begin{array}{c}\text { Mean half wavelength } \\
(\mathrm{mm})\end{array}$ \\
\hline 0.125 & 12 & 1.401 & 1.355 & 0.819 & 15.67 \\
0.175 & 10 & 1.447 & 1.416 & 0.945 & 16.67 \\
\hline
\end{tabular}

TABLE 10: Mechanical properties of Kapton and Mylar membrane.

\begin{tabular}{lcccccc}
\hline Material & Thickness $(\mathrm{mm})$ & Density $\left(\mathrm{kg} / \mathrm{m}^{3}\right)$ & Poisson ratio & Modulus of elasticity $(\mathrm{GPa})$ & Tensile strength $(\mathrm{MPa})$ & Elongation $(\%)$ \\
\hline Kapton membrane & 0.025 & 1420 & 0.34 & 3.58 & 186.0 & 37.0 \\
Mylar membrane & 0.025 & 1390 & $0.38(\mathrm{MD})$ & $4.9(\mathrm{MD})$ & $200(\mathrm{MD})$ & $116(\mathrm{MD})$ \\
& & & $0.31(\mathrm{MD})$ & $5.1(\mathrm{TD})$ & $240(\mathrm{TD})$ & $91(\mathrm{TD})$ \\
\hline
\end{tabular}

TABLE 11: The geometrical features of two laminated membranes.

\begin{tabular}{lccccc}
\hline Material & $\begin{array}{c}\text { Number of } \\
\text { wrinkles }\end{array}$ & $\begin{array}{c}\text { Maximum } z \text {-direction } \\
\text { displacement }(\mathrm{mm})\end{array}$ & $\begin{array}{c}\text { Minimum } z \text {-direction } \\
\text { displacement }(\mathrm{mm})\end{array}$ & $\begin{array}{c}\text { Average height } \\
(\mathrm{mm})\end{array}$ & $\begin{array}{c}\text { Mean half wavelength } \\
(\mathrm{mm})\end{array}$ \\
\hline Al-Kapton & 12 & 1.355 & 1.401 & 0.819 & 15.67 \\
Al-Mylar & 12 & 1.393 & 1.419 & 0.861 & 15.55 \\
\hline
\end{tabular}

TABLE 12: The geometrical features of different ply angles laminated membranes.

\begin{tabular}{lccccc}
\hline Ply angles & $\begin{array}{c}\text { Number of } \\
\text { wrinkles }\end{array}$ & $\begin{array}{c}\text { Maximum } z \text {-direction } \\
\text { displacement }(\mathrm{mm})\end{array}$ & $\begin{array}{c}\text { Minimum } z \text {-direction } \\
\text { displacement }(\mathrm{mm})\end{array}$ & $\begin{array}{c}\text { Average height } \\
(\mathrm{mm})\end{array}$ & $\begin{array}{c}\text { Mean half wavelength } \\
(\mathrm{mm})\end{array}$ \\
\hline 0 & 12 & 1.393 & 1.419 & 0.861 & 15.55 \\
45 & 12 & 1.365 & 1.348 & 0.855 & 15.55 \\
90 & 12 & 1.367 & 1.373 & 0.848 & 15.33 \\
\hline
\end{tabular}

TABLE 13: The geometrical features of different ply numbers laminated membranes.

\begin{tabular}{lccccc}
\hline $\begin{array}{l}\text { Sublayer } \\
\text { numbers }\end{array}$ & $\begin{array}{c}\text { Number of } \\
\text { wrinkles }\end{array}$ & $\begin{array}{c}\text { Maximum } z \text {-direction } \\
\text { displacement }(\mathrm{mm})\end{array}$ & $\begin{array}{c}\text { Minimum } z \text {-direction } \\
\text { displacement }(\mathrm{mm})\end{array}$ & $\begin{array}{c}\text { Average height } \\
(\mathrm{mm})\end{array}$ & $\begin{array}{c}\text { Mean half wavelength } \\
(\mathrm{mm})\end{array}$ \\
\hline 1 & 12 & 1.355 & 1.401 & 0.819 & 15.67 \\
2 & 7 & 1.982 & 1.898 & 1.32 & 25.2 \\
3 & 6 & 2.029 & 1.975 & 1.68 & 31.0 \\
4 & 5 & 2.315 & 2.25 & 1.90 & 37.0 \\
\hline
\end{tabular}

TABLE 14: The geometrical features of different ply modes laminated membranes.

\begin{tabular}{lccccc}
\hline Layer number & $\begin{array}{c}\text { Number of } \\
\text { wrinkles }\end{array}$ & $\begin{array}{c}\text { Maximum } z \text {-direction } \\
\text { displacement }(\mathrm{mm})\end{array}$ & $\begin{array}{c}\text { Minimum } z \text {-direction } \\
\text { displacement }(\mathrm{mm})\end{array}$ & $\begin{array}{c}\text { Average height } \\
(\mathrm{mm})\end{array}$ & $\begin{array}{c}\text { Mean half wavelength } \\
(\mathrm{mm})\end{array}$ \\
\hline Ply mode 1 & 6 & 2.029 & 1.975 & 1.68 & 31.0 \\
Ply mode 2 & 5 & 2.233 & 2.212 & 1.81 & 36.5 \\
Ply mode 3 & 5 & 2.246 & 2.225 & 1.82 & 36.25 \\
\hline
\end{tabular}

\section{Conclusion}

This paper describes the numerical simulation and experimental investigation of wrinkling patterns in laminated membranes subjected to external loads. The laminated thinshell element SHELL181 was used to model laminated membranes in ANSYS software. The nonlinear postbuckling analysis method was used to simulate the final configuration of the wrinkles. A 3D photogrammetry system was constructed and used to characterize the wrinkling patterns of laminated membranes. A comparison of the numerical results and experiments results indicates that the wrinkling pattern in experiments results agrees well with the corresponding analytical prediction; thus, the accuracy of the numerical analysis method is verified. The onset and growth processes for wrinkles in Al-Kapton laminated membranes were investigated; geometric features of the wrinkles change quickly. When the external load increases to a certain value, the number of 
wrinkles and the mean half wavelength change slightly. The design parameters such as material selection, ply number, ply angle, and ply mode are investigated in detail. The results indicate that membrane thickness and ply numbers of laminated membranes have a significant influence on the wrinkling patterns. The works of this paper are useful when applied to wrinkling simulation and shape control of space laminated membrane structures. In the future, the shape control strategy of laminated membranes based on Macro Fiber Composite (MFC) actuators will be investigated.

\section{Conflicts of Interest}

The authors declare that they have no conflicts of interest regarding the publication of this paper.

\section{Acknowledgments}

This work was supported by the National Natural Science Foundation of China (Grant no. 11402229) and the Zhejiang Province Natural Science Foundation (Grant no. LQ14A020003).

\section{References}

[1] Y. Xu and F.-L. Guan, "Structure design and mechanical measurement of inflatable antenna," Acta Astronautica, vol. 76, no. 1, pp. 13-25, 2012.

[2] E. B. Walter, J. M. Nathaniel, G. F. Paul et al., "Aerothermal ground testing of flexible thermal protection systems for hypersonic inflatable aerodynamic decelerators," in Proceedings of the 9th International Planetary Probe Workshop, pp. 1-11, Toulouse, France, June 2012.

[3] J. Hinkle, J. Lin, and J. Watson, "Deployment Testing of an Expandable Lunar Habitat," in Proceedings of the AIAA Space 2009 Conference \& Exposition, vol. 6447, pp. 1-9, Pasadena, Calif, USA, 2009.

[4] A. L. Adler and N. M. Mikulas, "Application of a wrinkled membrane finite Element approach to advanced membrane structures," in Proceedings of the AIAA Space 2001 Conference and Exposition, vol. 4646, pp. 1-11, AIAA, Albuquerque, NM, USA, 2001.

[5] X. Deng and S. Pellegrino, "Computation of partially inflated shapes of stratospheric balloon structures," in Proceedings of the 49th AIAA/ASME/ASCE/AHS/ASC Structures, Structural Dynamics, and Materials Conference, vol. 2133, pp. 1-18, AIAA, Schaumburg, Ill, USA.

[6] Y. W. Wong and S. Pellegrino, "Wrinkled membranes. Part II: analytical models," Journal of Mechanics of Materials and Structures, vol. 11, no. 1, pp. 25-59, 2006.

[7] C. H. Jenkins, F. Haugen, and W. H. Spicher, "Experimental measurement of wrinkling in membranes undergoing planar deformation," Experimental Mechanics, vol. 38, no. 2, pp. 147152, 1998.

[8] Y. Lecieux and R. Bouzidi, "Numerical wrinkling prediction of thin hyperelastic structures by direct energy minimization," Advances in Engineering Software, vol. 50, no. 1, pp. 57-68, 2012.

[9] S. Kukathasan and S. Pellegrino, "Nonlinear vibration of wrinkled membranes," in Proceedings of the 44th AIAA/ASME/ ASCE/AHS/ASC Structures, Structural Dynamics, and Materials Conference, vol. 1747, pp. 1-11, AIAA, Norfolk, Va, USA, 2003.
[10] Z. Wang, S. Yang, D. Liu et al., "Nonlinear aeroelastic analysis for a wrinkling aeroshell/ballute system," in Proceedings of the 51st AIAA/ASME/ASCE/AHS/ASC Structures, Structural Dynamics, and Materials Conference, vol. 2879, pp. 1-22, AIAA, Orlando, Fla, USA, 2010.

[11] E. M. Haseganu and D. J. Steigmann, "Analysis of partly wrinkled membranes by the method of dynamic relaxation," Computational Mechanics, vol. 14, no. 6, pp. 596-614, 1994.

[12] M. Kashiwa and J. Onoda, "Wrinkling analysis using improved dynamic relaxation method," AIAA Journal, vol. 47, no. 7, pp. 1601-1607, 2009.

[13] R. Rossi, M. Lazzari, and R. Vitaliani, "Simulation of lightweight membrane structures by wrinkling model," International Journal for Numerical Methods in Engineering, vol. 62, no. 15, pp. 2127-2153, 2005.

[14] Y. L. Guo, X. Q. Liu, and Z. M. Wan, "Influence of strain rate on mechanical properties of Al/Polymer film composite material," Physics Examination and Testing, vol. 6, pp. 18-20, 2004 (Chinese). 


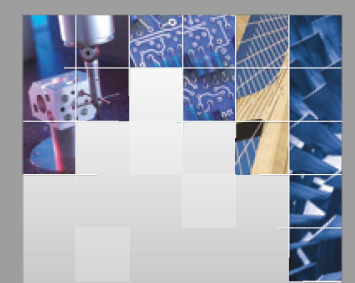

\section{Enfincering}
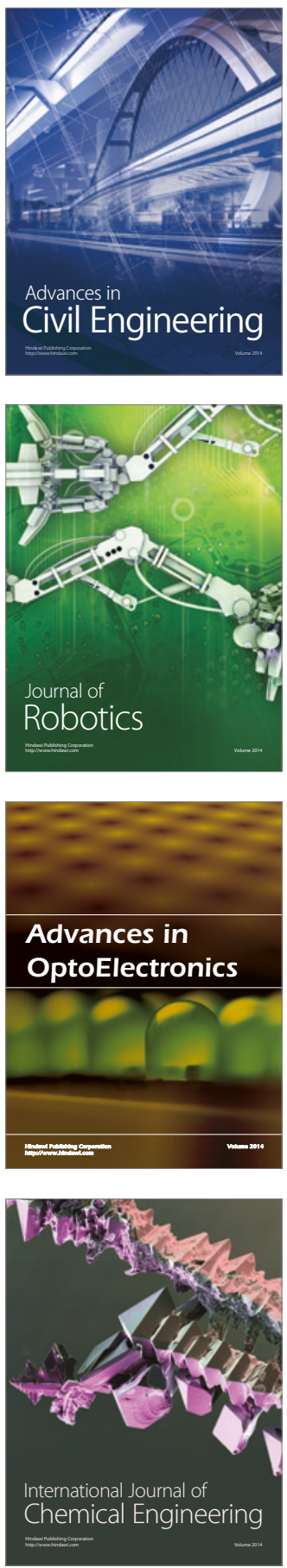

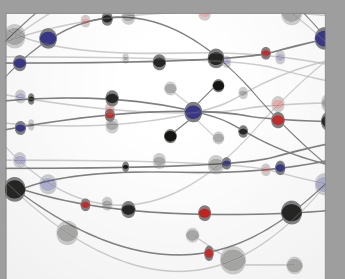

The Scientific World Journal

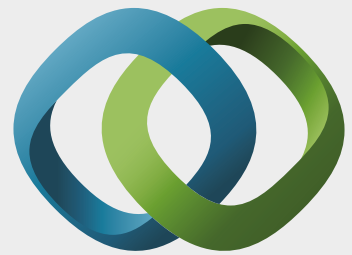

\section{Hindawi}

Submit your manuscripts at

https://www.hindawi.com
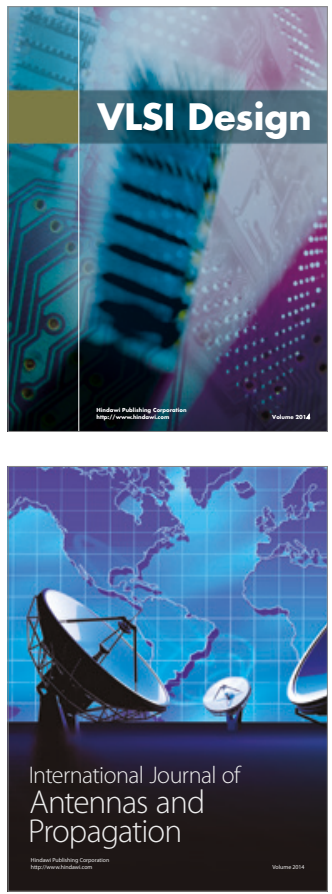

\section{Rotating}

Machinery
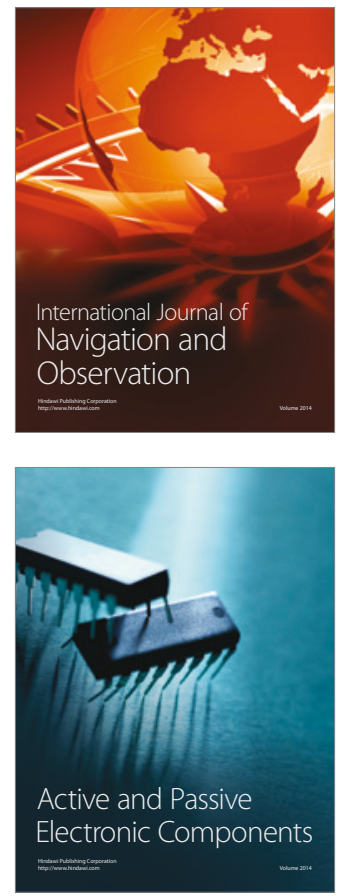
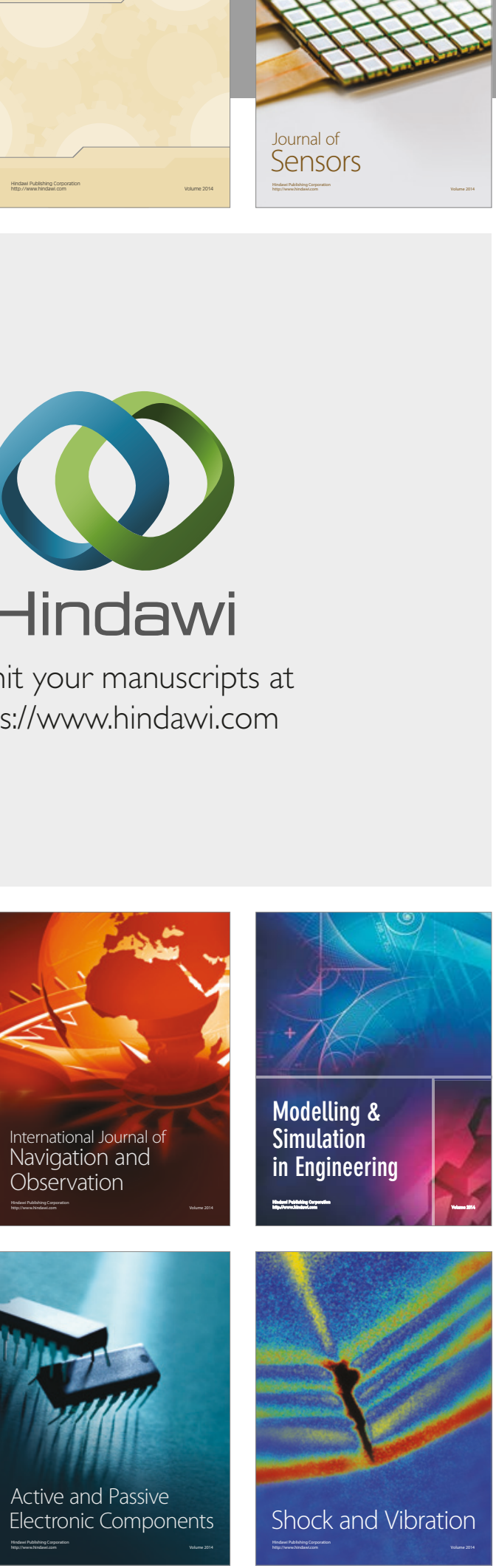
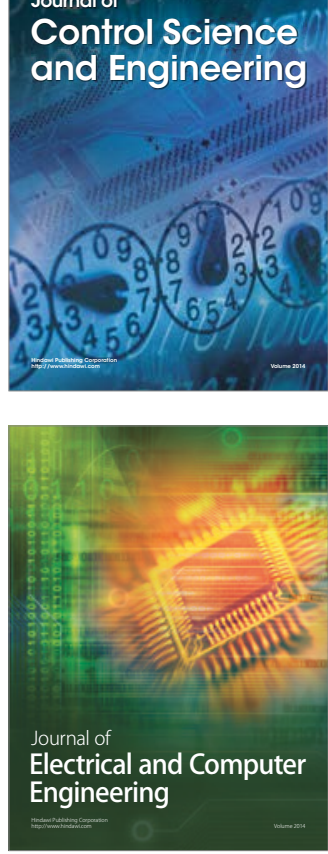

Distributed

Journal of

Control Science

and Engineering
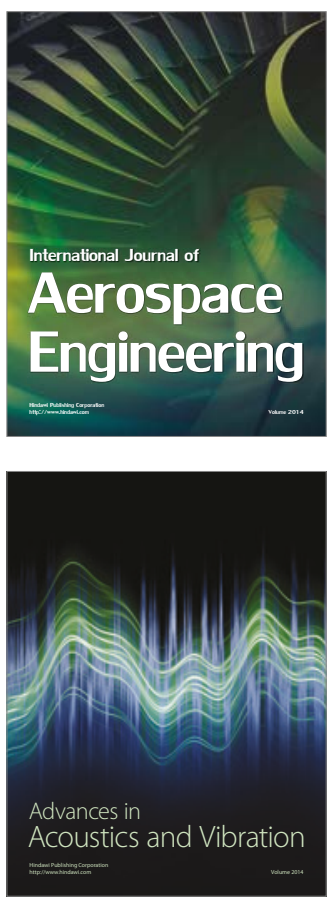

Sensor Networks 